\title{
Successful Surgical Correction of Osteosarcoma in a Buck
}

\author{
G.U. Yadav*, D.U. Lokhande, A.T. Yamgar, P.S. Dakhane and Adarsh Bijapur \\ Department of Veterinary Surgery \& Radiology, Bombay Veterinary College, Parel, \\ Mumbai - 12, India \\ *Corresponding author
}

\begin{abstract}
A B S T R A C T
\section{Keywords}

Goat, Osteosarcoma, Oral growth, Lower jaw

Article Info

Accepted:

10 October 2018

Available Online:

10 November 2018

A 14 months old male goat with growth on lower jaw was presented to the Bai Sakrabai Dinshaw Petit Hospital for Animal, an affiliated animal hospital to Bombay Veterinary College, Mumbai. On thorough clinical examination, it was revealed that extensive growth on lower jaw was present since last two and half months. On palpation the growth was big in size, hard and firmly attached to lower jaw, hard, big in size like. The history from animal owner revealed that the growth was painless and progressively increased in size over a period of time. There was involvement of incisor teeth of lower jaw and horizontal ramus of mandible. The growth was removed surgically under light sedation with Triflupromazine hydrochloride @ $0.03 \mathrm{mg} / \mathrm{kg} \mathrm{BW}$ administered intravenously and bilateral mental nerve blocks using $2 \%$ lingocaine $\mathrm{HCl}$. Histopathological examination revealed it was as osteosarcoma.
\end{abstract}

\section{Introduction}

Correct dentition is of critical importance to the maintenance of body condition/weight gain in sheep and goat. The eruption of the milk teeth and permanent teeth, occur in mammals following a determined order and in chronologic periods relatively independent of the animal's physiological state. If poor body condition is a presenting complaint in the adult small ruminant, a thorough dental exam is warranted (Vigal and Machordom, 1985). Ruminants have narrow mouths that do not open very far, thus hindering visual exam of the molars. Careful palpation through the cheeks will give preliminary information, but a thorough oral exam requires use of a mouth speculum, gag or bite block (either homemade or designed for sheep), a good flashlight or headlamp, and proper sedation. Dental disorders in goat and sheep can result in a range of clinical presentations (weight loss, abnormal appearance of incisors, cud-staining, swelling of the jaw, malocclusion of the jaw) (Canpolat et al., 2017).

Osteosarcoma refers to a group of primary malignant neoplasm affecting bone. Osteosarcoma of jaws is a rare, aggressive malignant mesenchymal tumor which is characterized by the formation of osteoid tissue. It constitutes $5 \%-13 \%$ of all cases of skeletal osteosarcomas. Jaw osteosarcomas usually occur in $4^{\text {th }}$ decade of life. The maxilla and mandible are equally involved. The mandibular tumors arise more frequently in 
the posterior body and ramous (Kaur and Singh, 2015). Present report deals with an unusual case of osteosarcoma in a 14 months aged buck and its successful surgical correction.

\section{Case history}

A buck aged 14 months was presented to the animal hospital with history of growth on lower jaw since last two and half months. The detail history of animal owner revealed that buck had eaten the leaves of some unknown toxic plant followed by development of inflammatory swelling on anterior part of lower jaw. The animal was treated by local veterinarian for swelling of lower jaw but had not responded to treatment. Further the growth started growing slowly since last 2.5 months.

Through clinical examination revealed that growth was hard, big apple like, painless firmly attached to lower mandible and progressively increased in size in period of 2.5 months. There was involvement of incisor teeth of lower jaw and vertical ramus of mandible. The buck was showing clinical signs of salivation and difficult to take food and water. The buck was taking some food by sides of growth. On radiological examination, there was soft tissue swelling on lower jaw involving horizontal ramus of mandible. Haematobiochemical parameters were within normal physiological limits and it was decided to perform complete removal of growth under light sedation and local infiltration anesthesia.

\section{Surgical treatment}

In preoperative treatment rehydration therapy and hematinic treatment was given for first 3 days. After aseptic preparations, light sedation with triflupromazine hydrochloride @0.03 $\mathrm{mg} / \mathrm{kg} \mathrm{BW}$, IV was administered. The bilateral mental nerve blocks were achieved using 2\% lignocaine hydrochloride. An elliptical incision was taken at the base of growth. After blunt dissection of subcutaneous fascia, base of growth was approached and severed. The blood vessels were ligated with using catgut no. 1-0. The growth was completely excised by surgical removal. The subcutaneous facia of the lower lip were sutured with lower mandible with catgut no 1-0 and the wound was dressed as open wound.

Postoperatively, Inj. Streptopenicillin @ $10 \mathrm{mg} / \mathrm{kg}$. was administered I.M. for 5 successive post-operative days, Inj. Meloxicam @ $0.2 \mathrm{mg} / \mathrm{Kg}$ B.wt. for 3 postoperative days and daily dressing was performed for 12 post-operative days with betadine and Rexidine - $\mathrm{M}$ ointment. The animal showed uneventful recovery.

On histopathological examination, microscopically it was revealed that ostoblastic stroma and sarcomatous connective tissue those merged gradually with each other. The matrix was diffusely fibrillated. Spindle and stellate cells were arranged in wavy fascicule and whorls. Pleomorphism was high. Nuclei varied in shaped from round, oval, spindle to compact thread; showed granular chromatin and frequently conspicuous nucleoli. The mass was vascularized. Multifocal mild degree lymphocytic infiltration was observed.

\section{Results and Discussion}

Osteosarcoma may malignant and are very rare in ruminants (Tyagi and Singh, 1994). Intraoral sarcoma is a very rare disease and may constitute approximately $1 \%$ of all head and neck cancers and only $0.14 \%$ of intraoral malignancies (Gorsky and Epstein, 1998).

The present case was a young buck having 14 months age. The buck was presented with the history of swelling probably produced by consumption of some toxic leaves which subsequently development into growth. 
Int.J.Curr.Microbiol.App.Sci (2018) 7(11): 1322-1326

Osteosarcoma in Male Goat
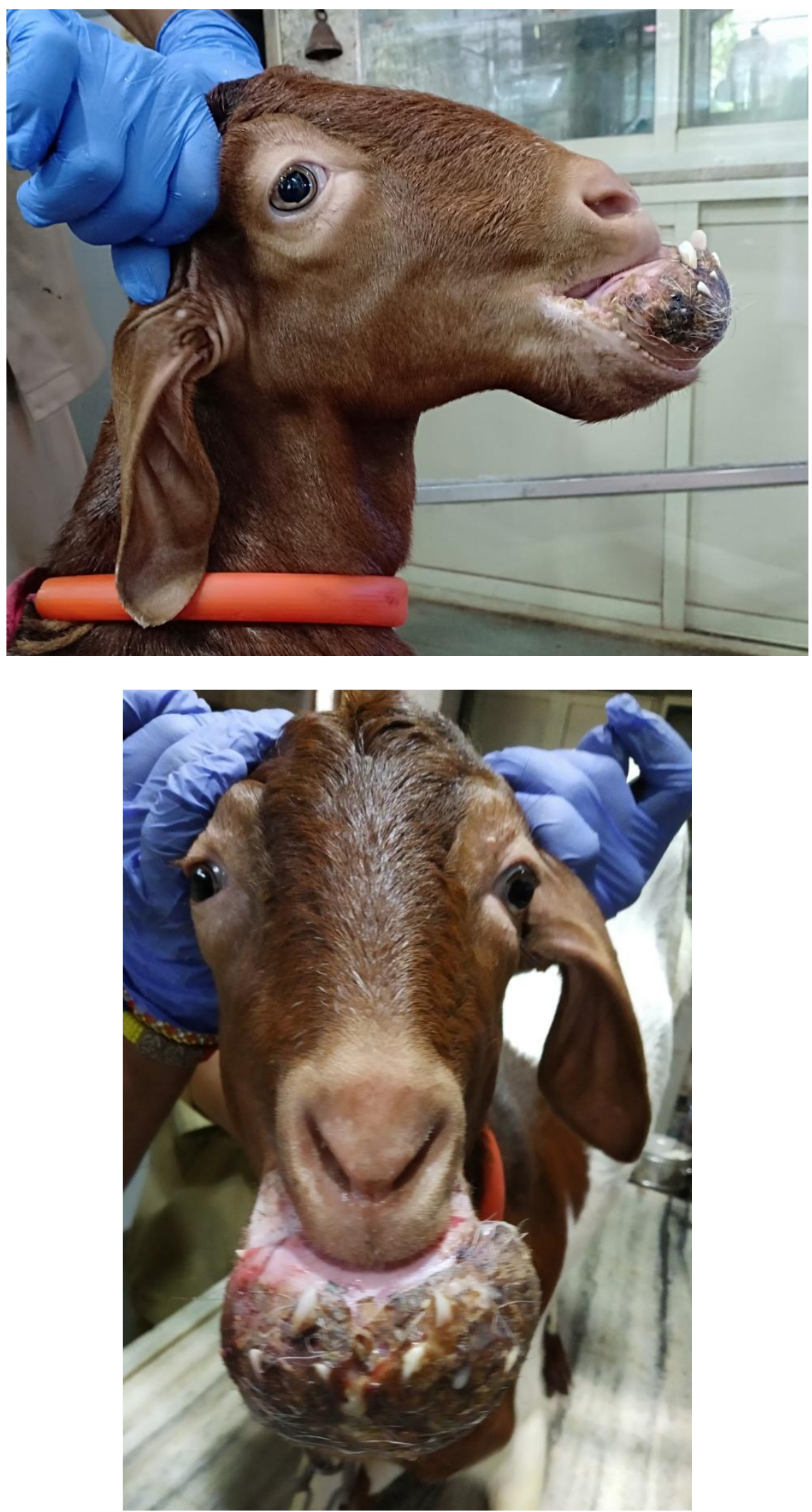


\section{Surgical excision of osteosarcoma}

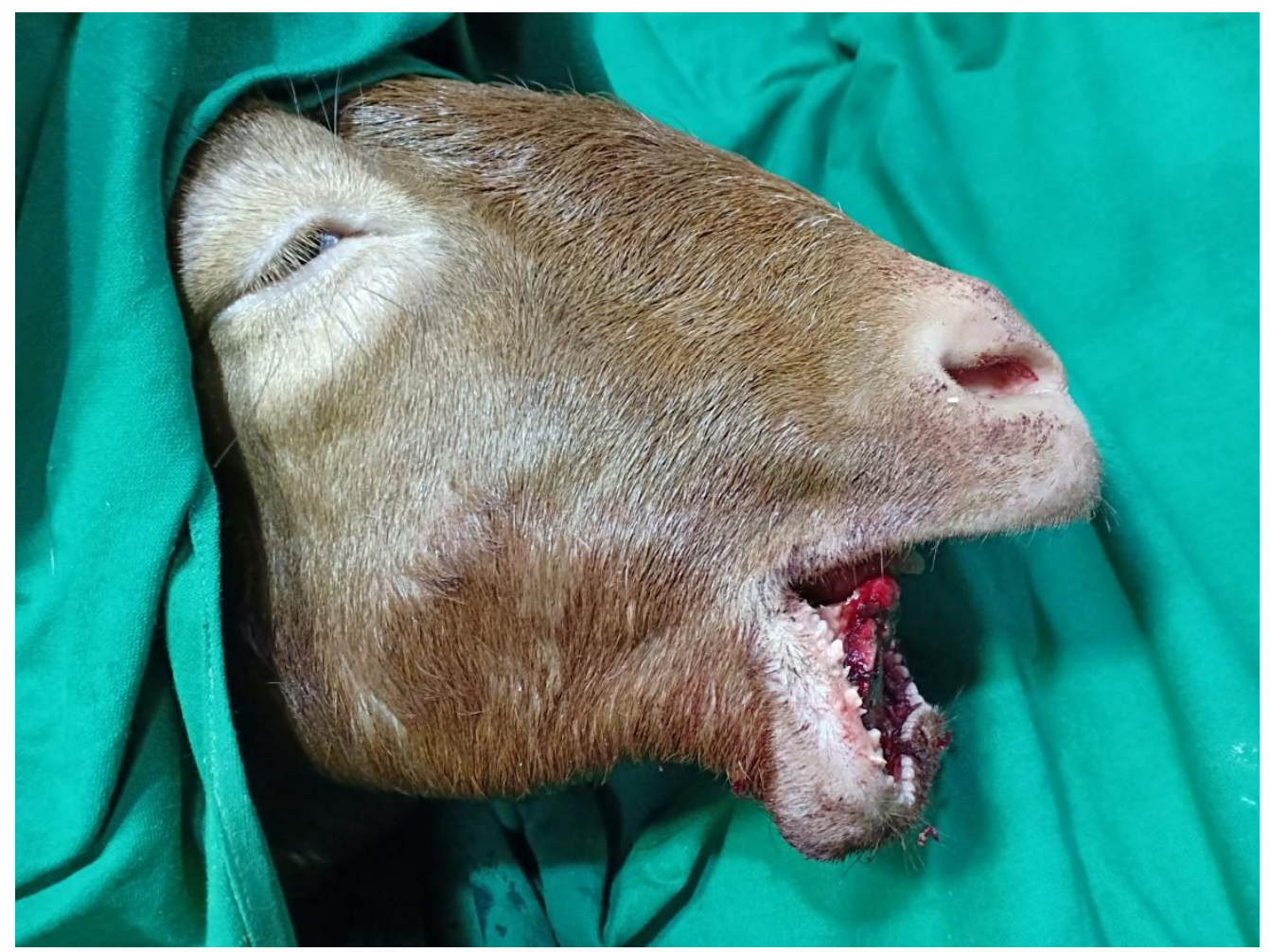

The exact cause of osteosarcoma was not known but the predisposing factors like irritation may initiate the condition. In the present case the irritation caused by the toxic plant eaten by animal might have resulted in swelling and the predisposition of osteosarcoma. Jenner et al., (2003) and Livesey et al., (1986) also reported that unknown etiology for osteosarcoma although trauma, viral infection, exposure to radiation, and genetic factors have been hypothesized as predisposing factors.

The growth was firmly attached to lower mandible, hard, big apple like, painless and progressively increased in size in 2.5 months Bush et al., (2007) mentioned that osteosarcomas are firm expansive and mineralized mass that distorated the normal tissue and produces necrosis of adjacent areas.

In the present case there was involvement of incisor teeth of lower jaw and vertical ramus of mandible. The osteosarcomas always involve the incisor teeth of lower jaw. Bush et al., (2007) reported that osteosarcomes may involve head, maxilla and mandible. The buck was showing clinical signs of salivation and difficulty in take food and water.

The buck was taking some of the food by sides of growth. This may be due to inability to take food and water by enlarged growth. Barber et al., (1983) also reported that osteosarcoma is rare tumor and occurs in maxilla and mandible of young horses which causes the disruption of face and interference with normal mastication.

Radiological examination showed soft tissue swelling on lower jaw involving horizontal ramous of mandible. Tyagi and Singh (1994) described osteosarcoma on radiograph as osteolytic and sclerotic changes with soft tissue swelling and elevated periosteum and calcification of bone. 
The growth was surgically removed by surgical excision under light sedation and bilateral mental nerve blocks which resulted in uneventful recovery.

Histopathological examination revealed ostoblastic stroma and sarcomatous connective tissue those merged gradually with each other. The matrix was diffusely fibrillated. Spindle and satellite cells were arranged in wavy fascicule and whorls. Pleomorphism was high. Nuclei varied in shaped from round, oval and spindle to compact thread; showed granular chromatin and frequently conspicuous nucleoli. The mass was vascularized. Multifocal mild degree lymphocytic infiltration was seen. Sheikh et al., (2010) reported that Osteosarcomas are categorized histologically into osteoblastic, chondroblastic, fibroblastic subtypes depending upon the predominant type of extracellular matrix present. The term osteosarcoma refers to a heterogenous group of primary malignant neoplasms affecting bone forming or mesenchymal tissues having a histopathological evidence of osteogenic differentiation. It is a spindle cell neoplasm and accounts for almost 40- $60 \%$ of all bone sarcomas.

\section{References}

Barber SM, Clark EG, Fretz PB (1983) Fibroblastic tumor of the premaxilla in two horses, J Am Vet Med Assoc 182:700-702
Bush J. M., R. L. Fredrickson, and E. J. Ehrhart (2007) Equine Osteosarcoma: A Series of 8 Cases, Vet Pathol 44: 247249.

Gorsky M, Epstein JB (1998) Head and neck and intra-oral soft tissue sarcomas. Oral Oncol 34: 292-296.

Ibrahim Canpolat, Enis Karabulut, Sema Cakir (2017) The Effect on Production Loss of Dental Disorders in Adult Goats, Journal of Agriculture and Veterinary Science, Volume 10, Issue 8 Ver. I, PP 76-80.

Jenner F, Solano M, Gliatto J, Lavallee S, Kirker- Head C (2003) Osteosarcoma of the tarsus in a horse, Equine Vet $\mathrm{J}$ 35: 214-216.

Kaur H, Singh A (2015) Osteosarcoma of jaw - Case report and review of literature, www.ijmds.org, 4(1), 653-657.

Livesey MA, Wilkie I.W. (1986) Focal and multifocal osteosarcoma in two foals. Equine Vet J., 18:.407-410.

Sheikh Soheyl, Shambulingappa Pallagatti, Amit Aggarwal, Deepak Gupta, Nidhi Puri, Amit Mittal (2010) Osteosarcoma of maxilla: A case report, J Clin Exp Dent., 2(3):117-20

Tyagi R.P.S. and Singh J. (1994) Text book of Ruminant Surgery, Cbs publisher and distributors.

Vigal C R and A Machordom, (1985) Tooth Eruption and Replacement in the Spanish Wild Goat, Acta Theriologica. 30(19), 305-320.

\section{How to cite this article:}

Yadav, G.U., D.U. Lokhande, A.T. Yamgar, P.S. Dakhane and Adarsh Bijapur. 2018. Successful Surgical Correction of Osteosarcoma in a Buck. Int.J.Curr.Microbiol.App.Sci. 7(11): 1322-1326. doi: https://doi.org/10.20546/ijcmas.2018.711.153 